\title{
PROGERIA SYNDROME
}

\author{
Lt Col MM HARJAI*
}

MJAFI 1999; 55 : 261-262

KEYWORDS: Hutchinson Gilford syndrome;Progeria; Undescended testes.

\section{Introduction}

$\mathbf{P}$ rogeria is also known as the Hutchinson Gilford syndrome. Though the condition is easily recognisable, its cause is unknown. It occurs sporadically and is very rare. We report a case of progeria associated with bilateral undescended testes. No such association has been found as yet in the available literature.

\section{Case Report}

A seven-years-old child was admitted with complaints of absence of both testes in the scrotum since birth. Examination revealed a short statured child weighing $14 \mathrm{~kg}$ and a height of 55 $\mathrm{cm}$. The patient had a large head with a small face and large eye balls. Forehead was bald with prominent scalp veins. There was overcrowding and irregularity of incisor teeth. The skin was thin, dry, wrinkled and inelastic with generalised lack of subcutaneous fat. Nails were atrophic. Abdomen was protuberant. Short clavicles, stooped body, thin limbs and prominent joints were also

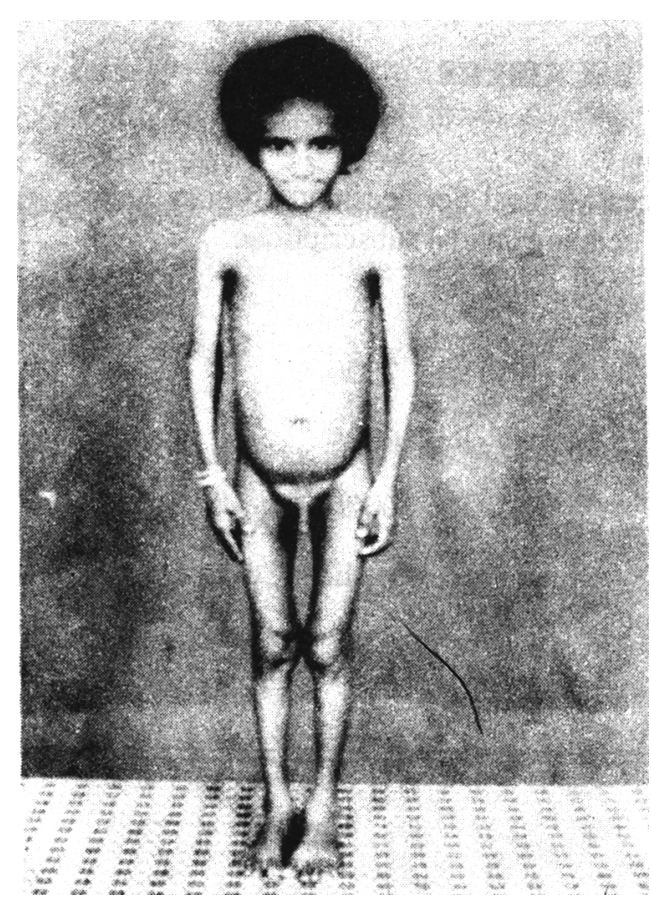

Fig. 1: Front view of the progeric patient showing large head, small face prominent eyes, prominent ribs, thin limbs, skeletal hypolpasia and bilateral undescended testes present. He was walking with wide based shuffling gait. The systemic examination and neurodevelopmental examination were normal. Scrotal examination revealed underdeveloped and empty scrotal sacs on both sides with bilateral undescended testes (Figs 1 \&2). Bilateral orchidopexy was done by fixation of the testis in a pouch between the scrotal skin and dartos. Post-operative recovery was uneventful. Patient is under close follow up.

\section{Discussion}

Progeria is a rare syndrome with an estimated incidence of 1 in 8 million. Although children with progeria have the appearance of premature aging or senility, the term is misleading because the reported cases of progeria have not manifested any or most physical or biochemical aspects of old age. Although first described in 1886, only about 100 cases of progeria are reported in the international literature.

Often children with progeria appear normal at birth

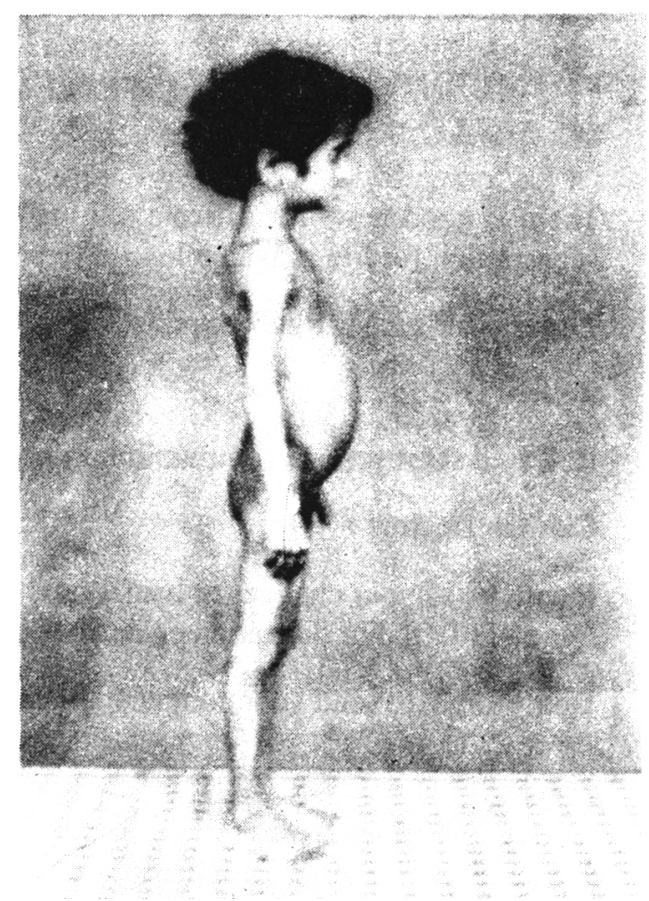

Fig. 2: Lateral view of the progeric patient showing peaked nose, potbellied abdomen, stooped body and prominent joints.

*Reader and Pediatric Surgeon, Department of Surgery, Armed Forces Medical College, Pune 411040. 
and then progressively, and rather rapidly develop the characteristic features during early childhood. The usual presentation is failure to grow and develop during the second year of life and by the tenth year growth has virtually caesed. The multiple defects of the syndrome involves the skin, fat, skeleton, nails and teeth. The cardiovascular system is involved at a later stage. The classical clinical features of this entity are well exemplified in our case.

The mechanical effect of the intermuscular pressure of the abdominal muscles contribute in normal descent of the testis by pushing it towards the scrotum. Poor muscular development in cases of progeria appears to be a likely cause of the bilateral undescended testes in this case. However, abonormalities of collagen found in this disease, can also affect the pulling function of the gubernacultum.

The diagnosis of progeria can be made at a glance and confirmed by radiological findings which include premature fusion of epiphyses. There is as yet no specific therapy available for this condition, but physiotherapy has been found to be effective in preventing the contractures. Progeric patients age at eight times the normal rate and develop accelerated atherosclerosis. Most die of cardiac or cerebrovascular disease between 6 and 19 years of age with a mean of 13 years [1].

In summary, a rare association of undescended testes and progeria is presented with a review of the condition. This entity is of considerable interest because of its striking features of premature aging.

\section{REFERENCES}

1. De Busk FL \& Brown WT. Progeria. In:Nelson text book of pediatrics, 15th edn, Eds Nelson WE, Behrman RE, Kliegman RM, Arvin AM. Philadelphia, WB Saunder co, 1996,pp 1996-1997. 